\title{
Crystal structures of human soluble guanylate cyclase catalytic domains: promiscuity of the dimer interface and a potential allosteric site
}

Opher Gileadi, Charles Allerston, Frank von Delft

From 6th International Conference on cGMP: Generators, Effectors and Therapeutic Implications Erfurt, Germany. 28-30 June 2013

\section{Background}

Soluble guanylate cyclase (sGC) catalyses the synthesis of cyclic GMP in response to nitric oxide. The enzyme is a heterodimer of homologous $\alpha$ and $\beta$ subunits, each of which is composed of multiple domains.

\section{Results}

We present here crystal structures of a heterodimer of the catalytic domains of the $\alpha$ and $\beta$ subunits, as well as an inactive homodimer of $\beta$ subunits. This first structure of a metazoan, heteromeric cyclase provides several

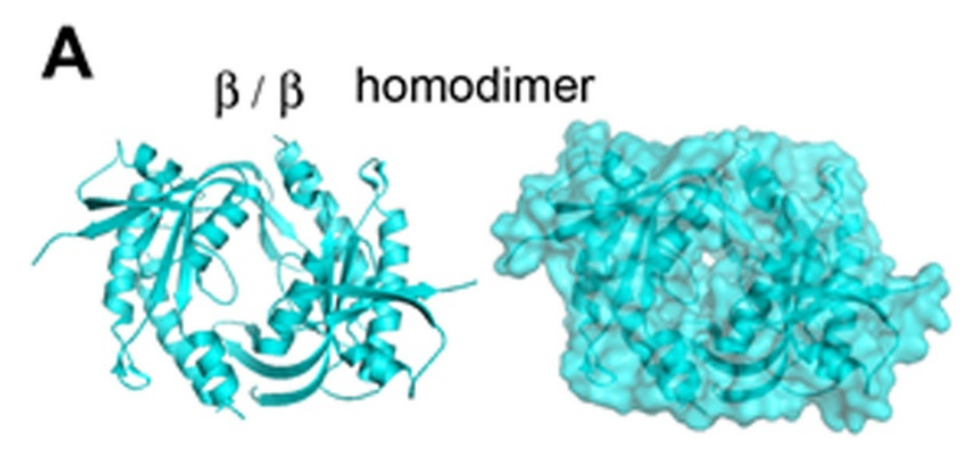

B $\alpha / \beta$ heterodimer
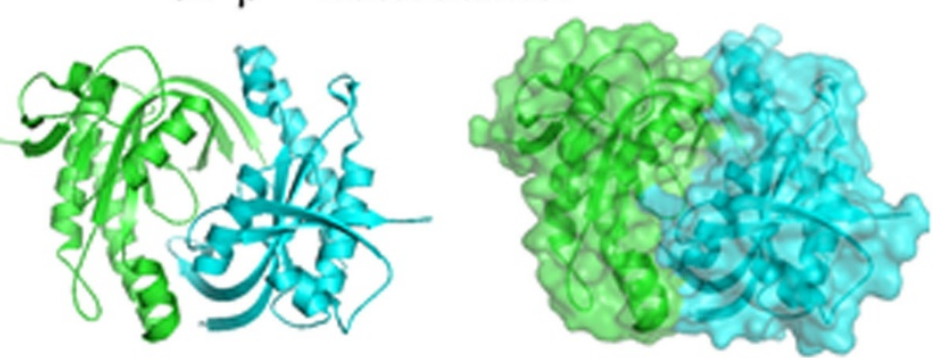

Figure 1 Schematic structures of the catalytic domains of human sGC: A. Homodimer of $\beta$ subunits, B: Heterodimer of $\alpha / \beta$ subunits.

\footnotetext{
* Correspondence: Opher.gileadi@sgc.ox.ac.uk

Structural Genomics Consortium, University of Oxford, Oxford OX3 7DQ, UK
} 
observations. First, the structures resemble known structures of adenylate cyclases and other guanylate cyclases in overall fold and in the arrangement of conserved active-site residues, which are contributed by both subunits at the interface. Second, the subunit interaction surface is promiscuous, allowing both homodimeric and heteromeric association; the preference of the full-length enzyme for heterodimer formation must derive from the combined contribution of other interaction interfaces. Third, the heterodimeric structure is in an inactive conformation, but can be superposed onto an active conformation of adenylate cyclase by a structural transition involving a $26^{\circ}$ rigid-body rotation of the $\alpha$ subunit. In the modelled active conformation, most active site residues in the subunit interface are precisely aligned with those of adenylate cyclase. Finally, the modelled active conformation also reveals a cavity related to the active site by pseudo-symmetry. The pseudosymmetric site lacks key active site residues, but may bind allosteric regulators in a manner analogous to the binding of forskolin to adenylate cyclase. This indicates the possibility of developing a new class of small-molecule modulators of guanylate cyclase activity targeting the catalytic domain.

Published: 29 August 2013

\section{Reference}

1. Allerston CK, von Delft F, Gileadi O: Crystal structures of the catalytic domain of human soluble guanylate cyclase. PLoS One 2013, 8:e57644.

doi:10.1186/2050-6511-14-S1-015

Cite this article as: Gileadi et al:: Crystal structures of human soluble guanylate cyclase catalytic domains: promiscuity of the dimer interface and a potential allosteric site. BMC Pharmacology and Toxicology 2013 14(Suppl 1):015.
Submit your next manuscript to BioMed Central and take full advantage of:

- Convenient online submission

- Thorough peer review

- No space constraints or color figure charges

- Immediate publication on acceptance

- Inclusion in PubMed, CAS, Scopus and Google Scholar

- Research which is freely available for redistribution

Submit your manuscript at www biomedcentral.com/submit 